DOI: $10.20287 /$ doc.d25.ac01

\title{
Paisagem sem significados profundos: uma análise dos comentários em Fata Morgana (1971)
}

\author{
Francisco Gabriel Rêgo \& Geovana Freitas Paim*
}

Direção: Werner Herzog

Fotografia: Jörg Schmidt-Reitwein

Edição: Beate Mainka-Jellinghaus

Roteiro: Werner Herzog

Produção: Joschi Arpa

Elenco: Lotte H. Eisner, Wolfgang von Ungern-Sternberg, James William

Gledhill, Eugen Des Montagnes

Músicas: Leonard Cohen, Wolfgang Amadeus Mozart, Third Ear Band, Blind

Faith

Duração: 79'

Ano: 1971

Línguas: Alemão, Ddogon e Inglês

Cor: Colorido

Som: Estéreo

\section{Paisagens, miragens e incertezas}

A expressão Fata Morgana trata-se de uma miragem resultante do deslocamento de ar em virtude da diferença de temperatura em paisagens. Fata Morgana é, por conseguinte, um tipo de miragem por meio do qual os objetos que se encontrem no horizonte adquirem uma aparência distorcida, e que, como afirma o senso comum, assemelham-se à castelos, como nos contos de fadas (fig. 1). O próprio significado desse termo aponta para essa perspectiva, já que, do italiano, Fata Morgana, traduz-se como Fada Morgana, uma referência, à meia-irmã do Rei Artur, e que tinha a capacidade de confundir

Francisco Gabriel Rêgo: Universidade Federal do Sul da Bahia - UFSB, Instituto de Humanidades, Artes e Ciências - IHAC, Nanook - Grupo de Análise de Documentário - UFBA. 45986-000, Teixeira de Freitas, Brasil. E-mail: francisco1gabriel@gmail.com

Geovana Freitas Paim: Universidade Estadual de Feira de Santana - UEFS, Departamento de Ciências Humanas e Filosofia - DCHF, Grupo de Pesquisa Dinâmica dos Territórios - UFBA. 44088612, Feiras de Santana, Brasil. E-mail:

geovanapaim@gmail.com 
o observador ao modificar sua aparência. Por assim dizer, o título do documentário é uma referência direta a ideia de ilusão ótica presente no efeito de miragem.

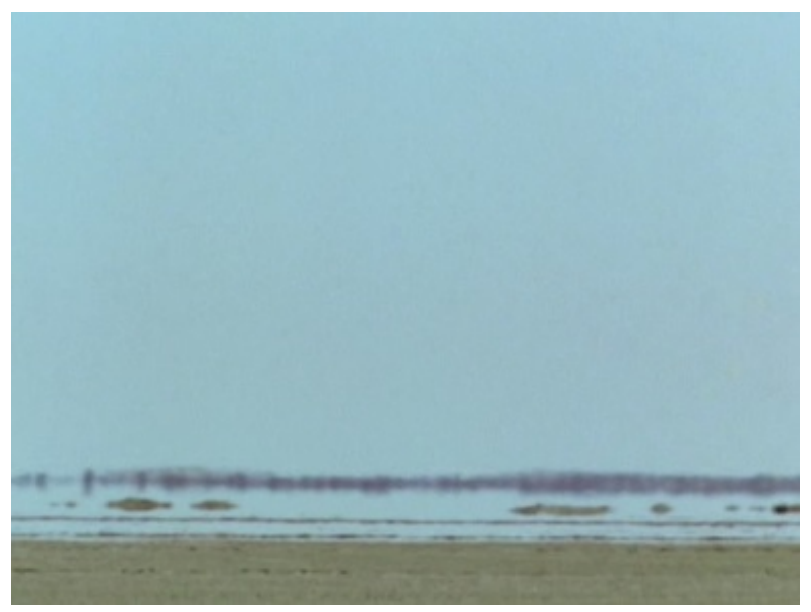

Figura 1. 04'09"

Filmado em três diferentes locais (República Centro-Africana, em Camarões e nas Ilhas Canárias), o documentário pode nos parecer, à princípio, pouco preciso quanto ao seu espaço de realização. Por meio de um espaço diegético apresentado por paisagens incertas, transfiguradas em um horizonte de miragens em plano gerais e traveling, cuja dimensão espacial parece transpor os limites e fronteiras. Aparentemente constituído por imagens que buscam reproduzir uma espécie de efeito no olhar do espectador, o documentário delineia uma paisagem constituída pela miragem e pela indeterminação.

Diante do olhar dos expectadores a paisagem é delineada, reforçando a ideia apresentada por Berque (2012), de uma paisagem em estreita relação com os "esquemas de percepção, de concepção e de ação". A paisagem se apresenta tendo como base a cultura e sociedade. Esta, por sua vez, carregaria as contradições comuns ao ato de perceber e estar no mundo, ao relacionar significados e subjetividades, em uma experiência perceptiva. Tal relação (homem-paisagem) envolveria aspectos significativos para a experiência humana, suas memórias, temporalidades e representações. Na paisagem convergiriam, assim, os sentidos presentes na relação entre a sociedade, o espaço e a natureza, em um "ecúmeno", uma experiência complexa e sucessiva "por infinitos laços de co-determinação" (p.239). 
Dessa forma, a dúvida e a imprecisão permeiam boa parte das interpretações do documentário. Desde uma imprecisão quanto a imagem do horizonte, ou na sequência inicial quando podemos nos deparar com uma repetição incessante do pouso de aviões, podemos conceber o documentário como uma espécie de miragem. Aqui, podemos, já nas primeiras cenas, ser levados a confrontar as imagens apresentadas e os comentários desenvolvidos pelo narrador. Por vezes, por meio das imagens descritivas de diferentes paisagens bem como do uso abundante do trevelling, podemos acreditar que se tratar-se de um filme de ficção científica. É interessante notar que as paisagens apresentam-se pela lógica da descoberta e não de uma forma cartesiana. Há uma constante integração entre objeto e sujeito.

Essa possibilidade aponta para o aspecto constitutivo da paisagem. No documentário, as paisagens seriam constituídas pela lógica de um estranhamento materializado pelo efeito ótico proposto, mas também pela diferença entre comentários e imagens. Tal como nas palavras de Eric Ames (2012), "para os estudiosos do documentário que aceitam a papel do estilo, paisagens de Herzog são constitutivas" (p. 50. Tradução nossa), se estabelecendo como uma categoria analítica do estilo desse cineasta: "Quando Herzog fala da paisagem, ele a usa para designar um lugar, um objeto, uma prática representacional, ou uma maneira de ver". (P. 49. Tradução nossa).

Analisando especificamente a esse filme, Ames (2012) aponta que a paisagem tem uma função hipnótica no espectador ao proporcionar uma confusão na forma desse compreender o que de fato teria diante dos seus olhos, influência do chamado cinema de vanguarda americano (avant-garde), em especial, da obra de Jonas Mekas. Nessa perspectiva, a paisagem nos é apresentada pelo encantamento, nos convidando para um "ato de olhar" marcado pelo fascínio diante do desconhecido e daquilo que em primeiro momento não se apresenta de forma direta, em uma paisagem constituída pelo olhar dos expectadores: "a ideia de transe decorreria desse fascínio" (p. 55. Tradução nossa).

O fascínio da imagem e da descoberta de diferentes componentes da paisagem é um dos motes para o deslocamento da câmera pelos diferentes espaços. Esse movimento delineia um novo espaço que foge às conformações territoriais e espaciais das fronteiras constituídas sobre a égide do neocolonialismo na África, espaço onde se dá boa parte da realização. Nesse quesito, transpor fronteiras e barreiras, aponta para o papel constitutivo das miragens como um novo espaço, nos convidando como expectadores a atuar na composição desse novo espaço, forjado na capacidade interativa do espectador. Mas que história Fata Morgana nos conta? De quem fala e para quem é narrado? Tais perguntas apontam para o papel prevalente do espectador, bem como para importância da 
experiência sensorial proposta pelo documentário: uma experiência sensível, interpretativa e criativa por parte do expectador.

Do ponto de vista narrativo, o filme divide-se em três partes, tendo na presença dos comentários e autocomentários um papel importante. A primeira parte chama-se "Criação", e caracteriza-se por uma narração em over de caráter mitológico acerca do surgimento do universo. A segunda parte chama-se "Paraíso", em que podemos observar o uso tanto de comentários e autocomentários, com um foco maior no homem inserido na paisagem. A terceira, denominada de "Idade Do Ouro", tal como na segunda parte, tem como base a articulação de comentários e autocomentários, de modo a constituir um discurso irônico acerca da relação do homem com o seu espaço e as formas utilizadas para a constituição do registro documental.

\section{Comentários, Criação e Contradição}

Na primeira parte do filme, podemos observar inicialmente uma sucessão de imagens de pousos de aviões. Compondo a paisagem, os aviões pousam diante da imagem de um horizonte pouco definido, espelhado, referência ao efeito ótico que nomeia o filme. Os aviões impõem à cena uma sucessão inquietante de pousos, alcançando um chão pouco delimitado aos olhos do espectador. As imagens excessivamente alongadas no horizonte, como em espelho d'agua, dota o plano de uma certa fluidez, e que compõe uma imprecisão quanto aos elementos espaciais que compõe plano geral: a pista de pouso e o céu (Fig. 2).

A primeira parte do documentário, é marcado pela narração da teórica franco-alemã Lotte Eisner, do chamado Popol Vuh, mito do povo Quiché, da Guatemala, dando conta da criação do universo. Apesar de o discurso mitológico nos suscitar uma ideia de solidez, quando apresentada concomitante à paisagem sob o efeito ótico, podemos observar o surgimento de um conflito entre os significados desenvolvidos pela narração e pelo plano das imagens (fig. 3). Nessa perspectiva, imagens e comentários apresentam-se tensionados por meio de significados distintos, mas que articulados nos possibilitam expressar um efeito que será bastante explorado na estruturação do documentário: a diferença de significados entre imagem e comentários. Essa diferença instaura no filme uma imprecisão quanto à realidade objetivada. 


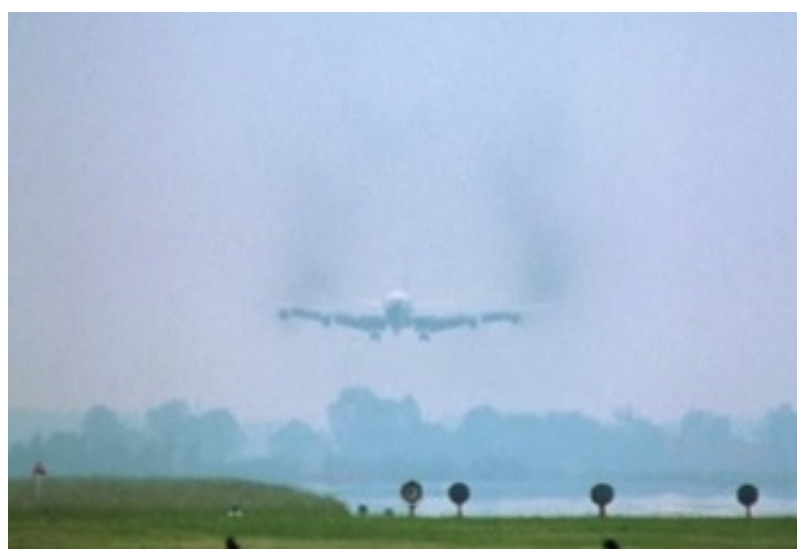

Figura 2. 0'58'

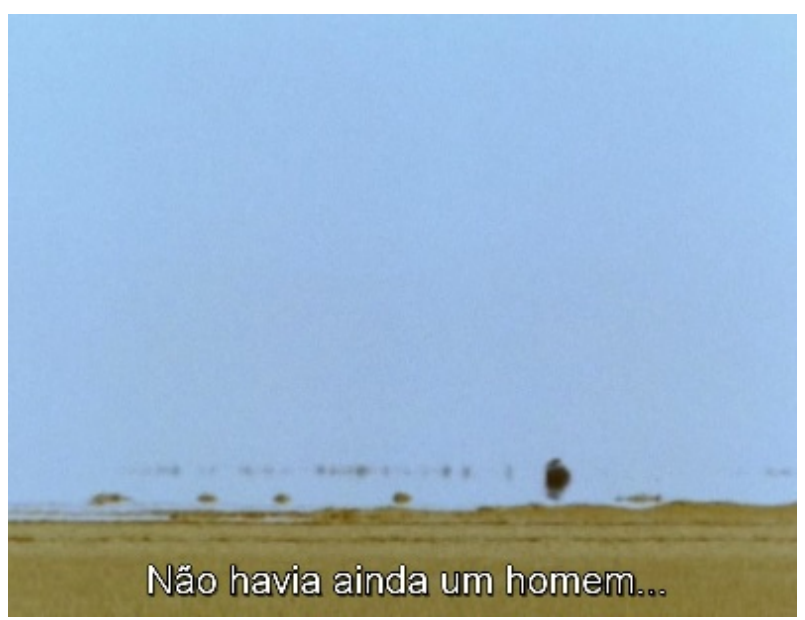

Figura 3. 06'33"

Dessa maneira, se, à princípio, por meio dos planos descritivos, acreditamos se tratar de algum deserto localizado no continente africano, não conseguimos delimitar espacialmente o meio eficiente ${ }^{1}$, o espaço onde se realiza a ação do realizador. Essa imprecisão é um dos objetivos principais do dire-

1. Para France (1998), o meio eficiente responde por todos os "elementos do ambiente direta ou indiretamente necessários ao exercício da atividade do agente do processo observado". O meio eficiente se opõe ao meio marginal: "elementos do ambiente cuja presença não é necessária ao exercício imediato da atividade do agente do processo observado nem à inteligibilidade da ação filmada" (p. 410) 
tor, que não parece se preocupar em deixar maiores pistas para a significação quanto ao espaço representado. Essa imprecisão materializa-se no plano no efeito de miragem do horizonte e na assimetria entre comentários e imagens. Se os comentários nos convidam a uma experiência mitológica e fundacional, o encadeamento das imagens nos coloca diante de uma experiência marcada pela fluidez e pelo deslocamento espacial.

Não obstante, o realizador nos propõe uma experiência criativa de um novo espaço, onde os significados são constituídos pela própria experiência do expectador diante das imagens. É interessante observar como os comentários buscam, por vezes, dotar de imprecisão a paisagem por meio de um sentido mitológico e fundacional. Muito embora, a narrativa mitológica possa sugerir uma precisão quanto aos significados das imagens, essa delimitação espacial apresenta-se superficial para os olhos do espectador, que facilmente pode se questionar acerca das origens tanto dos comentários, narrados em alemão, e das paisagens representadas. Por assim dizer, podemos afirmar que o filme, apesar de se basear em uma perspectiva sólida, engendra uma estrutura frouxa, quanto aos significados, de modo a convidar o expectador a uma imprecisão.

Tanto imagem quanto comentários nos convidam a uma experimentação de uma paisagem. Esse novo local se apresenta, à vista disso, diante das duas formas de espaços apresentados: a paisagem antropizada e não-antropizada. O filme aproxima a paisagens do homem, aquela constituída pela influência direta desse, das paisagens naturais, sem qualquer referência humana. $\mathrm{O}$ documentário nos permite, dessa maneira, observar uma naturalização da interferência humana na paisagem. É por meio dessa perspectiva que as imagens da fábrica no horizonte podem ser observadas como uma cadeia de montanhas, por exemplo. Aqui, o documentário aponta para o deslocamento das formas humanas, colocando elas nas mesmas condições das formas da natureza, como se o homem não houvesse ainda seu próprio espaço: "Então se manifestou com claridade que quando amanhece deve aparecer o homem. Então, dispuseram a criação e crescimento da arvores e os cipós e o nascimento da vida e a criação do homem" (FATA MORGANA, 1971, 13m 12s).

Por sua vez, o documentário estrutura-se diante da imprecisão desenvolvida entre comentários e as imagens. Essa impressão apresenta-se por meio da tentativa de criação de significados diante das imagens sob o efeito de miragem. Se as imagens são imprecisas, os comentários buscam dotá-las de sentido, por meio da criação e experimentação de uma nova paisagem. Entretanto, essa nova paisagem, ainda que constituída tendo por base os significados apresentados pelo narrador, é ainda uma miragem da realidade objetivada pelo realizador (Fig. 4 e 5). 


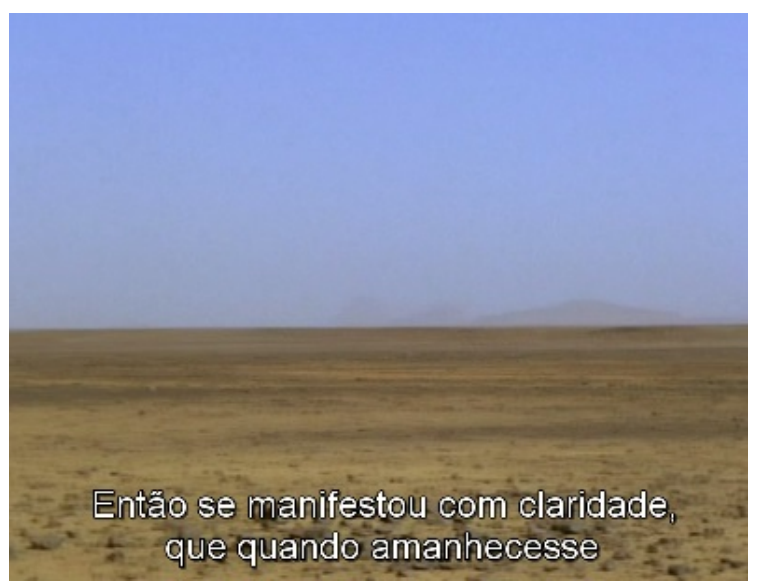

Figura 4. 13'30'

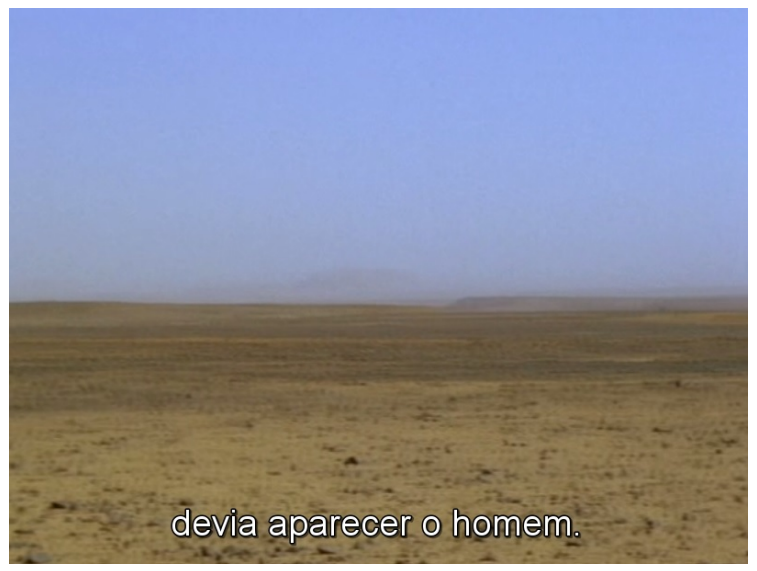

Figura 5. 13'35'

Da ideia de gênese e criação presente nos comentários mitológicos, surge um regime baseado na contradição do discurso criacional do mito do Popol Vuh. Esses comentários, ao abordarem o surgimento dos animais e dos homens, nos sãos apresentadas tendo por base imagens em completa discordância a esses comentários, nos colocando diante de em uma clara contradição: se por um lado podemos ouvir um narrador que nos conta do surgimento dos animais, podemos nos deparar com uma realidade pouco acessível à vida.

À vista disso, por meio da contradição entre comentários e imagens, o filme caminha em direção ao homem e ao seu espaço. A explicação mito- 
lógica, apesar de dar conta do meio físico, termina com uma explicação da diversidade do mundo pelo qual o homem estaria inserido. Aqui, o documentário constitui-se por uma lógica de aproximação das imagens ao plano, que passam a ser reproduzidas com pouca profundidade de campo, buscando criar um claro efeito de proximidade (fig. 6). Em outras palavras, o documentário parece criar um itinerário, partindo do deserto (Fig 7), em imagens marcada pela amplidão e por um horizonte pouco definido, para um conjunto de imagens com pouca profundidade, a simular uma ideia de aproximação.

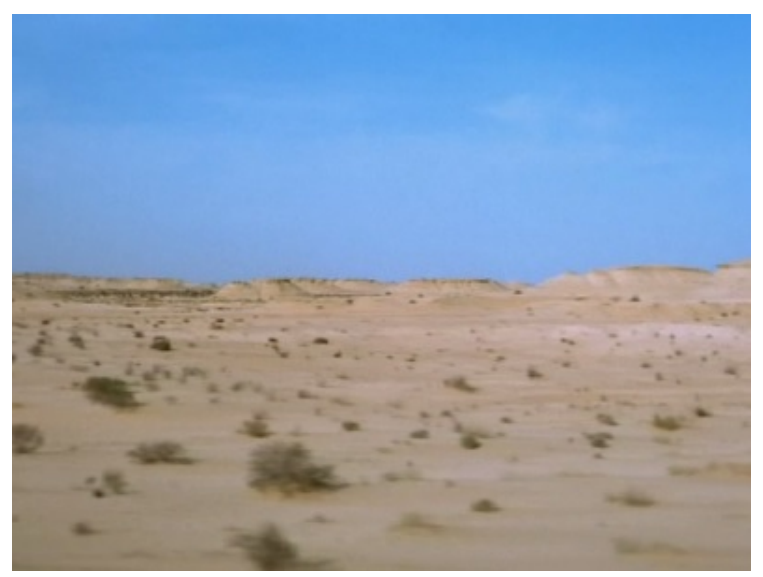

Figura 6. 20'05'

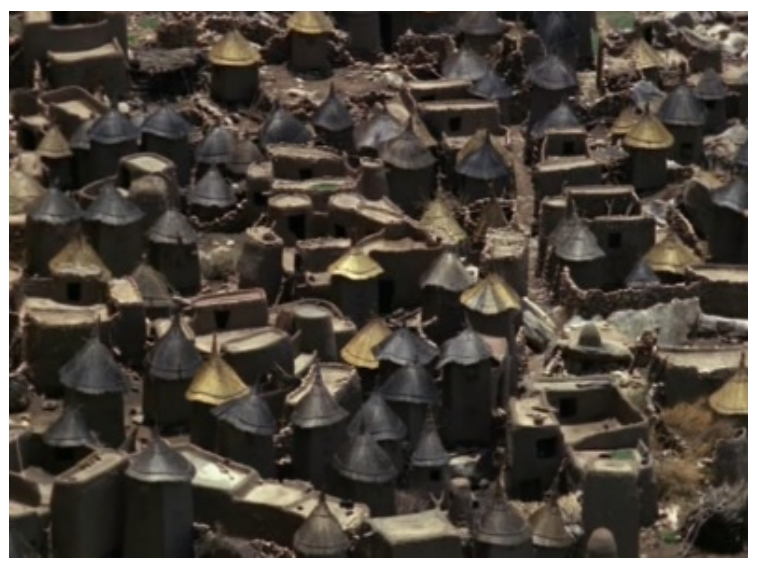

Figura 7. 34'12' 


\section{Autocomentários e Comentários}

A segunda parte do documentário, chamado "Paraíso", tem início com um autocomentário de um soldado cego. Esse comentário realizado no dialeto Ddogon, dialeto da tribo homônima do Mali, nos é apresentado propositadamente sem legenda, tal como a maioria dos autocomentários realizados por nativos. Como comentário principal dessa parte, temos a narrativa em voice over apresentadas pela mesma assimetria com as imagens, presente ao longo da segunda e terceira parte.

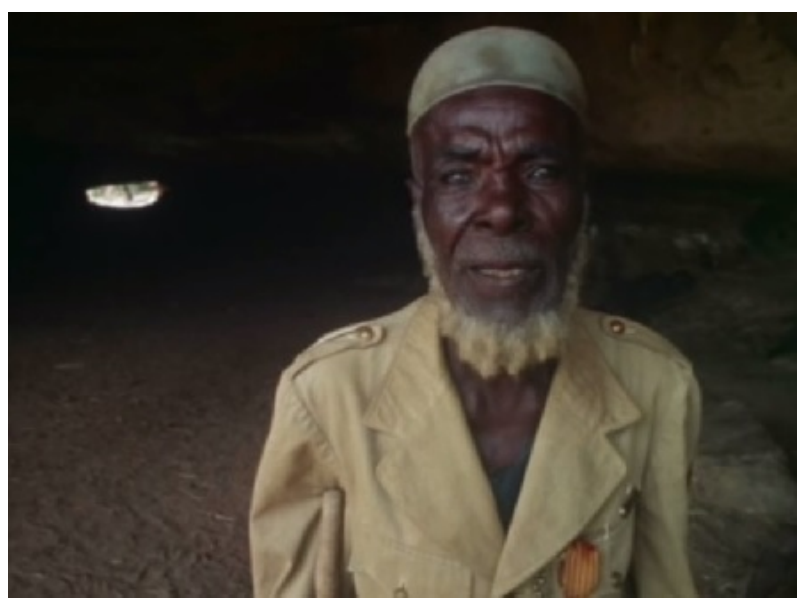

Figura 8. 38'47'

Nessa parte do filme, diferente da primeira, parece existir uma busca maior pelo homem, que são apresentados tendo por base o seu local no espaço. Essa paisagem marcada pela presença constante do homem é apresentada pelo narrador como "uma paisagem sem significados mais profundos", e que cruzando e atravessado pelo homem, se constitui como uma espécie de paraíso pouco acessível a vida humana. Como na primeira parte, o paraíso nos é apresentado pela contradição em imagens que contestam qualquer espécie de sentido estabelecido para essa palavra: "No paraíso só deus contempla..." (FATA MoRGANA, 1971, 41m 00s).

Como marca característica dessa segunda parte, podemos observar o uso de traveling, realizado não de forma convencional, como no momento em que a câmera cruza uma comunidade localizada, possivelmente, no meio do deserto, ao som da voz de Leonard Cohen. Além do traveling, podemos observar uma busca por adentrar ao espaço constituído pelo homem, por meio de uma inserção maior da câmera. Diferente do primeiro momento, onde prevalece 
os planos gerais e a movimentação panorâmica, podemos observar aqui o uso de planos fechados e médios a focar o homem inserido nesses espaços. Nessa perspectiva, o documentário busca construir um tensionamento maior entre o espaço e o homem do que na primeira parte. Se o espaço é criado, surge dali, como nas palavras mitológicas do Popol Vuh, um homem moldado ao meio, sujeito marcado pelas contradições e atributos da terra e da paisagem (fig. 9).

O paraíso pode ser pensado em termos contraditórios ao apresentado pelas imagens, contradição essa que instaura uma ironia diante da narração do realizador bem como da música (fig. 10). Essa ironia aponta para a própria potencialidade do documentário: propor uma experiência para além da realidade. Não obstante, no paraíso criado para os homens, o próprio homem é a matéria prima para a constituição do espaço.

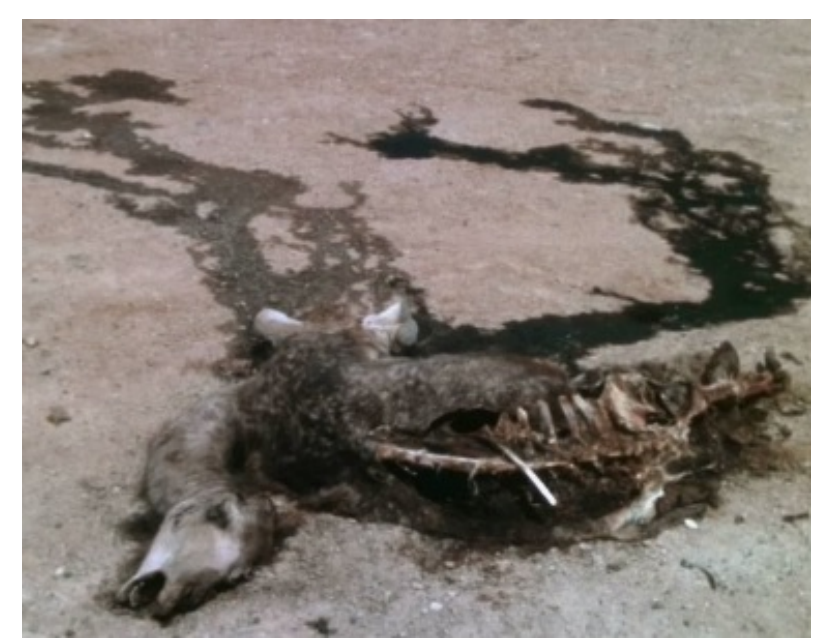

Figura 9. 40'52' 


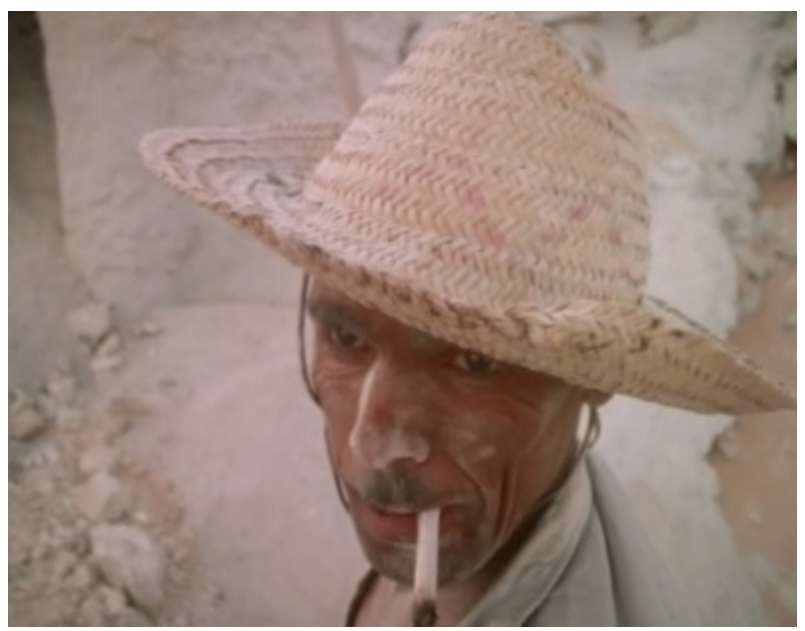

Figura 10. 43'58"

Por assim dizer, podemos observar os autocomentários de um possível biólogo ao apresentar a capacidade dos baramos em sobreviver a uma realidade tão inóspita à vida (fig. 11). Tal como o homem, esse animal se desenvolve tendo por base o seu meio, adaptando-se às adversidades, utilizando os limites do espaço como forma de modificar e criar-se. Talvez venha daí uma boa definição do Paraíso, o espaço para a superação das dificuldades e limites do homem, forma de reafirmar a sua capacidade de resistência e criatividade ao meio.

Além disso, podemos observar também, ainda na segunda parte, a existência de cenas contraditórias e com poucas ligações à maioria das sequências de imagens desérticas utilizadas durante boa parte do filme. Podemos situar, aqui, as imagens da piscina artificial, onde tartarugas nadam tranquilamente, bem como as imagens da praia e das crianças ao falarem para câmera enquanto repetem a frase: "guerra relâmpago é uma loucura". Nessas sequências é interessante observarmos como os comentários constroem um distanciamento das imagens ao acentuar a mesma ironia diante de um paraíso constituído à revelia das formas tradicionais. A imagem dos dois colegas de trabalho que cruzam ironicamente a paisagem constituída pelo homem diante do vazio da paisagem natural, nos permite atentar para as diferenças dos espaços pelo qual o homem se faz presente (fig. 12). 


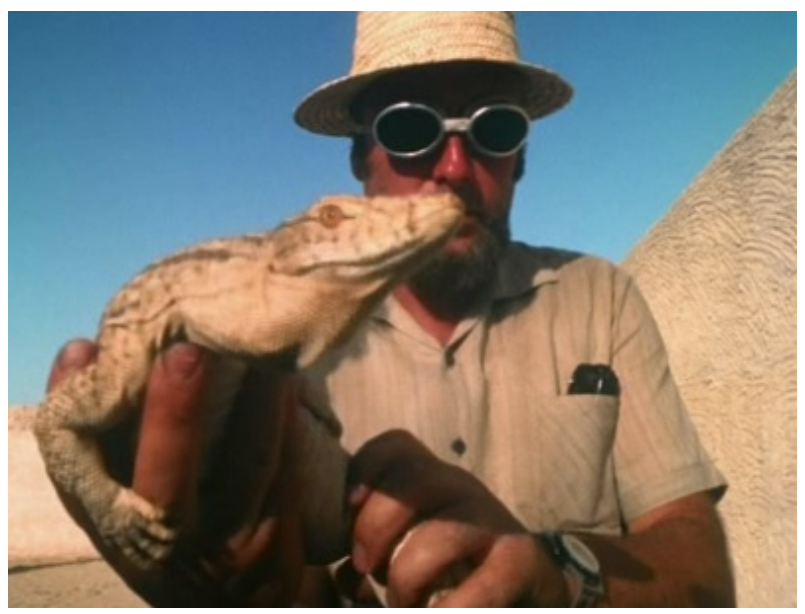

Figura 11. 46'10"

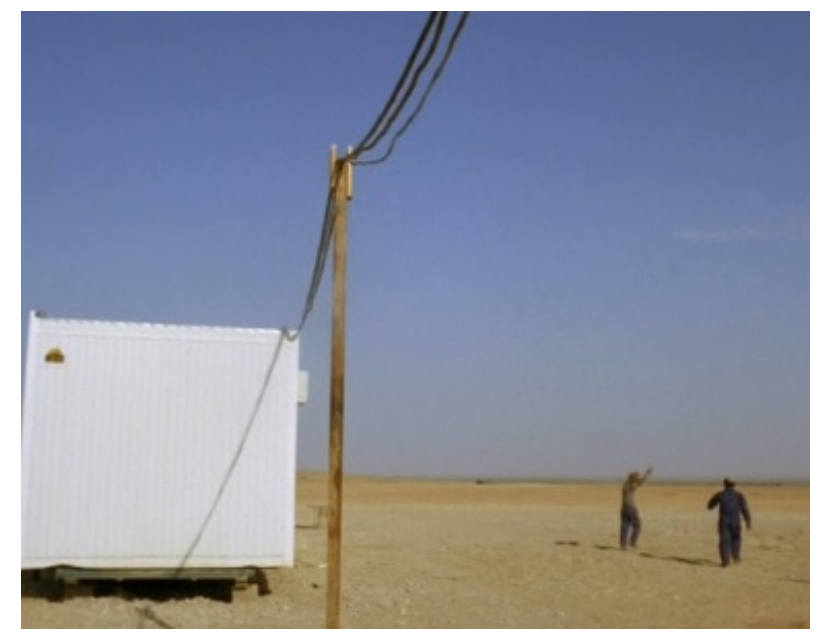

Figura 12. 52'20"

A terceira parte do documentário chama-se "A era do ouro" e continua seu foco nas pessoas. Contudo, diferente da segunda, é nessa parte onde podemos encontrar as cenas internas, realizadas na sua maioria com câmera parada. No início podemos perceber, tal como na parte anterior, o papel importante dos autocomentários, diferente da primeira parte. Apesar disso, os comentários desenvolvidos ainda continuam a ter um papel importante de contrapor-se às imagens. Se a expressão "Idade do ouro" pode suscitar qualquer espécie de 
opulência ou felicidade, nos deparamos com imagens onde os sujeitos filmados estão dominados por uma apatia, distante da narração em voice over. Os planos gerais da dupla musical têm o papel de nos aproximar do caricato e de uma representação teatralizada para esses sujeitos. Tal como personagens de uma encenação cômica, o grupo toca apenas para o registro do documentarista. Nessa sequência, os comentários buscam constituir a mesma assimetria com relação ao plano das imagens em que a banda, centralizada em um plano geral, nos apresenta aqueles sujeitos como dotados de uma apatia fora do comum (fig. 13):

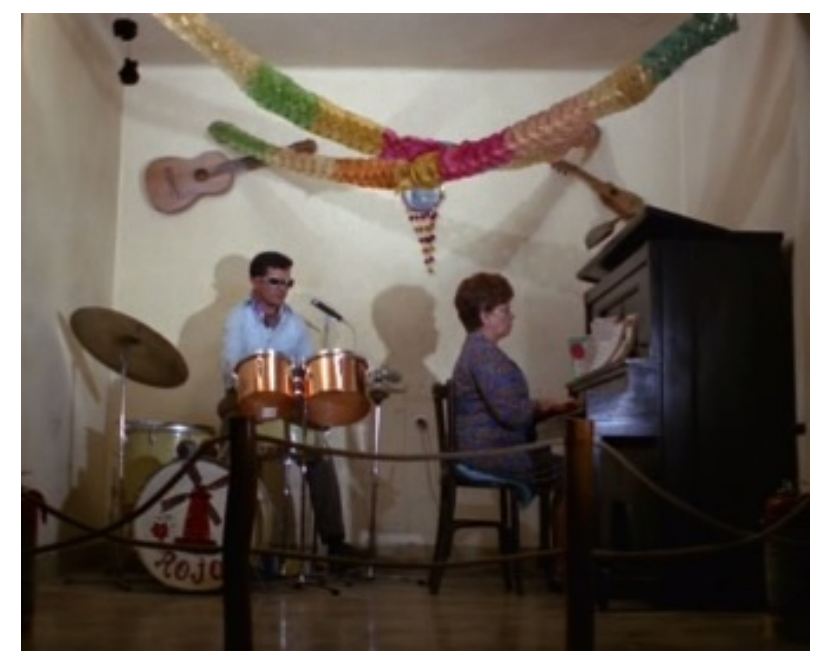

Figura 13. 63'11": na era dourada, ainda podem distinguir-se sonhos do paraíso...

Nessa parte final do documentário, podemos perceber ainda uma opção maior pela encenação em momentos bem específicos, tanto por meio das sequências que buscam constituir uma forma encenativa, como na música tocada pela dupla, ou dos turistas a acenarem constantemente para a câmera, ou pelo uso da encenação diante da câmera, a simular a filmagem do próprio documentário (fig. 14). Nessa encenação, especificamente, podemos perceber uma proposta de simulação da própria realização do documentário, por meio da presença de personagens que encenam a figura do realizador, que segura uma antiga filmadora, de um narrador, que lê um texto sobre a paisagem, e de um espectador em risadas sonoras diante de toda aquela encenação. 


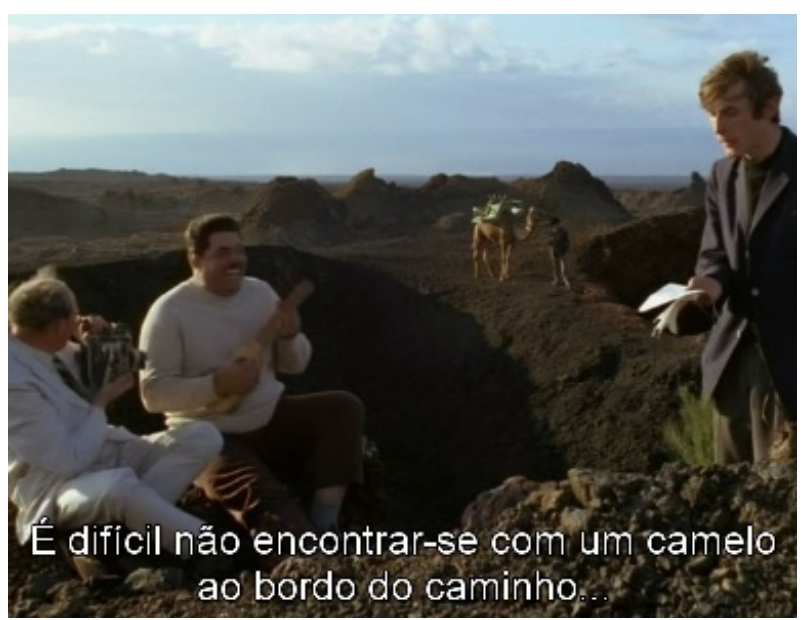

Figura 14. 71'04"

Aqui, tal como em outros momentos do documentário, podemos ouvir a mesma estratégia empregada: um narrador a referenciar a paisagem por meio de um discurso, dotando a paisagem de um novo sentido. Contudo diferente da primeira parte, a ironia intensifica-se por meio da encenação. Tal como os comentários, a paisagem aqui é construída, arquitetada e encenada. Aqui, é importante observar a ocorrência de uma inversão interessante tendo por base os comentários, que passam a ser autocomentados pela leitura do personagem a encenar a própria figura do narrador do filme, em uma inversão que busca repensar a própria condição do documentário e das estruturas que fundamentam a proposta narrativa e representativa: a incerteza de uma paisagem capaz de nos dizer das especificidades, contradições das novas formas de significarmos o nosso mundo.

\section{Referências}

Ames, E. (2012). Ferocious reality: documentary according to Werner Herzog. University of Minnesota Press.

Berque, A. (2012). Paisagem-marca, paisagem-matriz: elementos da problemática para uma geografia cultural. Geografia Cultural: uma antologia (1): 239-244. Rio de Janeiro: Eduerj.

France, C de (1998). Cinema e antropologia. Campinas: Unicamp.

Nichols, B. (2007). Introdução ao documentário. Campinas: Papirus. 
Tonelo, G. K. (2012). Werner herzog, documentarista: figuras da voz e do corpo. Dissertação de metrado, Universidad estadual de campinas.

Vanzo, F. (s.d.). (1970) Fata Morgana. Acessado em: 14/11/2016, http://marat onaherzog.blogspot.com.br/2013/10/1970-fata-morgana.html. Publicado em 11/11/2011.

\section{Filmografia}

Fata Morgana (1971), de Werner Herzog. 